\title{
Interactive comment on "Observations of iodine monoxide over three summers at the Indian Antarctic bases, Bharati and Maitri" by Anoop S. Mahajan et al.
}

\section{Anonymous Referee \#1}

Received and published: 30 December 2020

The paper by Mahajan et al. presents IO observation results measured with a MAXDOAS at two Indian Antarctic stations (i.e., Bharatic and Maitri) located in East Antarctica. Using a total of 4 data sets from the two stations over the three summers of $2015-1017$, the authors found that the vertical profiles of IO showed maximum levels near the surface with lower levels at higher altitude. The maximum observed mixing ratio of IO was around 2 ppt and therefore lower than what was measured in previous ground observations in West Antarctica. The 10 observations reported in this study were higher than the satellite measurements and the authors proposed that these are likely due to differences in sensitivities. The back trajectory analysis did not show a clear trend in the source of the airmass. Ground observations of halogen gas species 
are scarce in polar regions, especially of gas-phase iodine species, and therefore the sources and mechanism driving atmospheric iodine are poorly understood. This study brings in a unique data set which should be publishable after considering major revisions described below.

\section{General comments:}

In general, the introduction is lacking some previous studies on reactive halogen species in polar regions. The introduction gives an idea that iodine levels differ geographically, but more details would be helpful. Previous studies that show geographical discrepancies between the Arctic vs Antarctic and East vs West Antarctic should be discussed. For example, similar levels of $\mathrm{BrO}$ have been observed between the Arctic and Antarctic while much lower levels of atmospheric iodine have been reported in the Arctic (Hönninger et al., 2004; Pohler et al., 2010; Raso et al., 2017; Schonardt et al., 2008; Tuckermann et al., 1997) compared to the Antarctic. Moreover, both satellite and ground observations show discrepancies between the west and east Antarctica with the Weddell sea being an iodine hotspot. Some relevant references are included in the introduction but describing how previous studies show geographical differences in reactive iodine species would emphasize the uniqueness of the data set presented in the current study, which reports observations in East Antarctica.

For the previous observations presented in the introduction, it would be helpful to include the range or max levels observed and where and which season it was measured for each study. Only parts of the information are included for some studies.

Some background information on the implications of reactive halogen species on ozone depletion events (Barrie et al., 1988; Bottenheim \& Gallant, 1986; Kreher et al., 1997; Oltmans \& Komhyr, 1986) and new particle formation (Alicke et al., 1999; Allan et al., 2000; Carpenter et al., 1999; C. O'Dowd et al., 1999; C. D. O'Dowd et al., 1998) should be included. Adding background information on how reactive bromine and iodine species go through catalytic cycles that drive ozone depletion events and how the 
presence of iodine can accelerate this would be helpful.

In the second paragraph, the authors give examples of the possible source of reactive iodine gas species in Antarctica. It should be clear that previous observations at Halley Bay (Saiz-lopez et al., 2007) and the Weddell sea (Atkinson et al., 2012) proposed sea ice as the source of reactive iodine based on back trajectories and iodocarbon measurements in the sea ice. Additional studies that measured iodocarbons from coastal Antarctica (Carpenter et al., 2007; Fogelqvist \& Tanhua, 1995; Reifenhäuser \& Heumann, 1992), which can move up the brine channel in sea ice (Garrison \& Buck, 1989) and released to the atmosphere, should be discussed and included.

In the third paragraph, discrepancies in the vertical profile of reactive halogens between model simulations and observations are introduced. However, it is not clear throughout the paragraph on specifically 'what' the examples are referring to (e.g., IO, BrO or halogen species in general?). These should be clarified for each of the previous study that'scited.

Figure 8 seems to show one randomly chosen scan of IO vertical profile for each campaign. It is not very clear whether this one selected vertical profile or all the profiles for the whole campaign is what is being compared to previous observations at the Neumayer station and the Weddell sea. This should be clarified. Also, in Figure 8, it would be more helpful to show all the valid vertical profile scans for all four campaigns with a median (or mean) with standard deviations of both the vertical profiles and the surface. The averaged surface 10 levels for the whole campaign should be compared to previous observations rather than one randomly chosen scan.

As mentioned in the discussion (Ln 312-313), the satellite observation results were averaged over 2004-2011 and compared to the observations in this study. However, since reactive halogen species have strong seasonal variations, it would be better to average the summertime satellite observations of $I O$ (e.g., November to February) for Figure 9 and when comparing with the ground measurements from Bharati and Maitri.

Printer-friendly version

Discussion paper 
It should also be noted that uncertainties exist when averaging satellite observed IO concentrations within $500 \mathrm{~km}$ range of each station (the distance between the Neumayer station and the Maitri station is only $\sim 800 \mathrm{~km}$ ), especially when there are large variations of IO level within that distance as can be expected from Figure 9.

Specific comments:

Ln 40-42 I assume this is from Saiz-Lopez et al. (2007)? Please include reference. Ln 81 specify which type of model and what type of sources and chemistries were included in the model Ln 84 sources of 'what'? Ln 88 gradient of 'what'? Ln $187-189$ It seems like during ISEA-34, the winds were mostly E to NE while during ISEA-35 and ISEA-36, the winds varied more. Ln $220-221$ "For several days,..." specify if this is for all four campaigns or for a specific campaign. Ln 229-231 It should be noted that these are examples of one randomly chosen scan for each campaign. Ln 232-233 Rather than using 'several' or 'a few' for describing data flagged as 'bad' or 'valid', it would be better to just describe the \% (or \# of scans) that gave good data that were flagged 'valid'. (same with Ln 246 - 247) Ln 239 - 243 include standard deviation Ln 251 specify what 2.83X1012 molecules cm-2 is. Is this the average? Ln 261 specify altitude of 'surface'. Specify whether $0.2-1.3 \mathrm{pptv}$ range of $\mathrm{IO}$ is for all the four campaigns throughout the whole observations period with 'valid' scans or for the specific randomly chosen scan for each campaign shown in Figure 8. Ln 309 provide average and standard deviation of satellite observation of $\mathrm{IO}$ for each station (i.e., Bharati and Maitri) Ln 384-385 this sentence contradicts with Ln 187 that says most airmasses were from the ocean for all four campaigns.

When describing all the data sets, it's sometimes described as 'three campaigns' (e.g., Line 131, Line 319) or as 'four campaigns' (e.g., in figures captions), which could be confusing. It would be better to be consistent.

There are parts that needs rephrasing. For example: Ln $246-247$ is same as Ln 234 -235 Ln $327-329$ is the same as Figure S8 caption 
Figure 1 Add Dumont d'urville station in the figure and include references for each of the locations that previously reported IO.

Figure 2 is difficult to see since there are too many trajectories overlapping. A wider time resolution (e.g., $6 \mathrm{~h}$ or $12 \mathrm{~h}$ ) should be sufficient rather than trajectories every hour for the entire three summers.

Figure 3 Add frequency of each data (e.g., 5 min averaged?). It is difficult to interpret the wind directions and speeds during ISEA-35 and ISEA-36 since there are many days with two lines overlapping too much. One option might be smoothing it out by averaging and having one parameter as a marker (e.g., wind speed) and the other color coding (e.g., wind direction) the markers. Same with temperature and humidity, it might be easier to interpret the data if the $y$-axis scale is adjusted so that the two line (orange and black) don't overlap too much.

\section{Technical corrections:}

Ln 40 'year-long' study rather than 'long term'. Ln 139 NO2 at $220 \mathrm{~K}$ and $298 \mathrm{~K}$ Ln 156 at both stations Ln 164 Additionally, MAPA provides the option Ln 167 the estimated value ranged between Ln 225 of two example days Ln 230 Figure S3, and Figure S4 shows Ln 213- 232 IO VCDs, respectively, for all the campaigns. Ln 338 surface albedo is probably much higher Ln 340 on the retrieval results. (period missing)

Figure S6 data points extend outside the lower limit of $y$-axis

\section{References}

Alicke, B., Hebestreit, K., Stutz, J., \& Platt, U. (1999). lodine oxide in the marine boundary layer. Nature, 397, 572-573.

Allan, B. J., Mcfiggans, G., Plane, J. M. C., \& Coe, H. (2000). Observations of iodine 105(DII), 14363-14369. 
Atkinson, H. M., Huang, R. J., Chance, R., Roscoe, H. K., Hughes, C., Davison, B., Schönhardt, A., Mahajan, A. S., Saiz-Lopez, A., Hoffmann, T., \& Liss, P. S. (2012). lodine emissions from the sea ice of the Weddell Sea. Atmospheric Chemistry and Physics, 12(22), 11229-11244. https://doi.org/10.5194/acp-12-11229-2012

Barrie, L. A., Bottenheim, J. W., Schnell, R. C., Crutzen, P. J., \& Rasmussen, R. A. (1988). Ozone destruction and photochemical reactions at polar sunrise in the lower Arctic atmosphere. Nature, 334(14), 6-9.

Bottenheim, J. W., \& Gallant, A. G. (1986). Measurements of NOy species and O3 at 820 N Latitude. Geophysical Research Letters, 13(1), 113-116.

Carpenter, L. J., Sturges, W. T., Penkett, S. A., \& Liss, P. S. (1999). Short-lived alkyl iodides and bromides at Mace Head, Ireland: Links to biogenic sources and halogen oxide production. Journal of Geophysical Research Atmospheres, 104(D1), 16791689. https://doi.org/10.1029/98JD02746

Carpenter, L. J., Wevill, D. J., Palmer, C. J., \& Michels, J. (2007). Depth profiles of volatile iodine and bromine-containing halocarbons in coastal Antarctic waters. Marine Chemistry, 103(3-4), 227-236. https://doi.org/10.1016/j.marchem.2006.08.003

Fogelqvist, E., \& Tanhua, T. (1995). lodinated C1-C4 hydrocarbons released from ice algae in Antarctica. In: Grimvall A., de Leer E.W.B.(eds) Naturally-Produced Organohalogens. Envrionment \& Chemistry, vol 1. Springer, Dordrecht.

Garrison, D. L., \& Buck, K. R. (1989). The biota of Antarctic pack ice in the Weddell sea and Antarctic Peninsula regions. Polar Biology, 10(3), 211-219. https://doi.org/10.1007/BF00238497

Hönninger, G., Leser, H., Sebastián, O., \& Platt, U. (2004). Groundbased measurements of halogen oxides at the Hudson Bay by active longpath DOAS and passive MAX-DOAS. Geophysical Research Letters, 31(4), 1-5. https://doi.org/10.1029/2003GL018982 
Kreher, K., Johnston, P. V., \& Wood, S. W. (1997). Ground-based measurements of tropospheric and stratospheric BrO at Arrival Heights, Antarctica. Geophysical Research Letters, 24(23), 3021-3024. https://doi.org/10.1029/97GL02997

O’Dowd, C. D., Geever, M., Hill, M. K., Smith, M. H., \& Jennings, S. G. (1998). New particle formation: Nucleation rates and spatial scales in the clean marine coastal environment. Geophysical Research Letters, 25(10), 1661-1664.

Interactive

O'Dowd, C., Heard, D. E., McFiggans, G., Creasey, D. J., Smith, M. H., Lee, J. D., Pirjola, L., Pilling, M. J., Hoell, C., Kulmala, M., Plane, J. M. C., \& Allan, B. J. (1999). On the photochemical production of new particles in the coastal boundary layer. Geophysical Research Letters, 26(12), 1707-1710. https://doi.org/10.1029/1999GL900335

Oltmans, S. J., \& Komhyr, W. D. (1986). Surface ozone distributions and variations from 1973-1984 measurements at the NOAA geophysical monitoring for climatic change baseline observatories. Journal of Geophysical Research, 91(6), 5229-5236. https://doi.org/10.1029/JD091iD04p05229

Pohler, D., Vogel, L., Friess, U., \& Platt, U. (2010). Observation of halogen species in the Amundsen Gulf, Arctic, by active long-path differential optical absorption spectroscopy. Proceedings of the National Academy of Sciences, 107(15), 6582-6587. https://doi.org/10.1073/pnas.0912231107

Raso, A. R. W., Custard, K. D., May, N. W., Tanner, D., Newburn, M. K., Walker, L., Moore, R. J., Huey, L. G., Alexander, L., Shepson, P. B., \& Pratt, K. A. (2017). Active molecular iodine photochemistry in the Arctic. Proceedings of the National Academy of Sciences, 114(38), 10053-10058. https://doi.org/10.1073/pnas.1702803114

Reifenhäuser, W., \& Heumann, K. G. (1992). Determinations of methyl iodide in the Antarctic atmosphere and the south polar sea. Atmospheric Environment Part A, General Topics, 26(16), 2905-2912. https://doi.org/10.1016/0960-1686(92)90282-P

Saiz-lopez, A., Mahajan, A. S., Salmon, R. A., Bauguitte, S. J., Jones, A. E., Roscoe, H. 
K., \& Plane, J. M. C. (2007). Boundary Layer Halogens in Coastal Antarctica. Science, 348(July), 348-352. https://doi.org/10.1126/science.1141408

Schonardt, A., Richter, A., Wittrock, F., Kirk, H., Oetjen, H., Roscoe, H. K., \& Burrows, J. P. (2008). Observations of iodine monoxide columns from satellite. Atmos. Chem. Phys, 8, 637-653.

Tuckermann, M., Ackermann, R., Golz, C., Lorenzen-Schmidt, H., Senne, T., Stutz, J., Trost, B., Unold, W., \& Platt, U. (1997). DOAS-observation of halogen radical-catalysed arctic boundary layer ozone destruction during the ARCTOC-campaigns 1995 and 1996 in Ny-Alesund, Spitsbergen. Tellus, 49B, 533-555.

Interactive comment on Atmos. Chem. Phys. Discuss., https://doi.org/10.5194/acp-2020-998, 2020. 